\title{
A SELECTIVE AND SENSITIVE LC-MS/MS METHOD FOR QUANTIFICATION OF FOUR POTENTIAL GENOTOXIC IMPURITIES IN ATAZANAVIR SULFATE DRUG SUBSTANCE IN TRACE LEVEL
}

\author{
SIVA JYOTHI N., VENKATNARAYANA MUVVALA*
}

Department of Chemistry, GITAM School of Science, GITAM (Deemed to be University) Rudram, Hyderabad, Telangana, India

*Email: vmuvvala2@gitam.edu

Received: 28 Jan 2021, Revised and Accepted: 16 Mar 2021

\begin{abstract}
Objective: The main objective of current research work is to develop and validate a rapid, sensitive and selective liquid chromatography-tandem mass spectrometry (LC-MS/MS) method for the trace analysis of four potential genotoxic impurities in Atazanavir Sulfate drug substance.

Methods: LC-MS/MS analysis of four potential genotoxic impurities was done on Acquity UPLC CSH C 18 (100 mm $\times 2.1 \mathrm{~mm}, 1.7 \mu \mathrm{m}) \mathrm{column}$. In this method, mobile phase A (10 mM ammonium acetate) mobile phase B (methanol: acetonitrile $(90: 10, v / v)$ with gradient run with the flow rate of 0.2 $\mathrm{ml} / \mathrm{min}$. The method was developed with the short run time of $13 \mathrm{~min}$. Triple quadrupole mass detector coupled with positive electrospray ionization was used for the quantification of genotoxic impurities in multiple reaction monitoring (MRM) mode.
\end{abstract}

Results: The method was linear in the range of $0.3 \mathrm{ppm}$ to $4.5 \mathrm{ppm}$ for BOC Hydrazine Acid impurity, BOC Epoxide and Keto impurity with a correlation coefficient not less than 0.9994 . The accuracy of the method was in the range of $99.26 \%$ to $105.71 \%$ for all four potential genotoxic impurities (PGIs). No impurities were identified in the Atazanavir Sulfate active pharmaceutical ingredient sample.

Conclusion: The proposed method is specific, linear, precise, accurate, robust and stable for the quantification of the four genotoxic impurities at very low levels.

Keywords: Atazanavir Sulfate, Genotoxic Impurities, LC-MS/MS, Multiple Reaction monitoring (MRM), Method Development and Validation

(C) 2021 The Authors. Published by Innovare Academic Sciences Pvt Ltd. This is an open access article under the CC BY license (https://creativecommons.org/licenses/by/4.0/) DOI: https://dx.doi.org/10.22159/ijap.2021v13i3.40911. Journal homepage: https://innovareacademics.in/journals/index.php/ijap

\section{INTRODUCTION}

Atazanavir (formerly known as BMS-232632) is an antiretroviral drug of the protease inhibitor (PI) class. Like other antiretroviral, it is used to treat infection of the human immunodeficiency virus (HIV). Atazanavir is distinguished from other PIs. It can be given once daily (rather than requiring multiple doses per day) and has lesser effects on the patient's lipid profile (the amounts of cholesterol and other fatty substances in the blood). Like other protease inhibitors, it is used only in combination with other HIV medications. The U. S. Food and Drug Administration (FDA) approved Atazanavir on June 20, 2003. Atazanavir Sulfate is a sulfate salt form of atazanavir, an aza-dipeptide analogue with a bis-aryl substituent on the (hydroxethyl)hydrazine moiety with activity against both wild type and mutant forms of HIV protease [1-4].

Atazanavir sulfate is chemically designated as (3S,8S,9S,12S)-3,12bis(1,1-dimethyl ethyl)-8-hydroxy-4,11-dioxo-9-(phenylmethyl)-6[[4-(2-pyridinyl)phenyl]methyl]-2,5,6,10,13-pentaazatetra

decanedioic acid dimethyl ester, sulfate (1:1). Its molecular formula is $\mathrm{C}_{38} \mathrm{H}_{52} \mathrm{~N}_{6} \mathrm{O}_{7} . \mathrm{H}_{2} \mathrm{SO}_{4}$, which corresponds molecular weight 802.9. According to the literature, the tert-Butyl 2-[4-(pyridine-2yl)benzyl]hydrazinecarboxylate (BOC Hydrazine) was identified as a potential genotoxic impurity due to the presence of hydrazine, and this one is a well-known alerting function for genotoxic activity. Tert-butyl\{(1S)-1-[(2R)-oxiran-2-yl]-2-phenylethyl $\}$ carbamate (BOC Epoxide) is identified as potential genotoxic impurity by the presence of epoxide. Tertiary butylester[(1S,2S)-3-chloro-2hydroxy-1-(phenylmethyl) propyl]carbamicacid (Acid impurity) and 3(S)-3-(tert-butoxycarbonyl)amino-1-chloro-4-phenyl-2-butanone (Keto impurity) has alert functional group of carbamates. The genotoxic alert for these impurities was identified through DEREK nexus software [5]. LHASA predictions derived out of DEREK nexus software report clearly indicate that those impurities are a very plausible entity that shows carcinogenicity, chromosome damage in vitro, and mutagenicity in mammals.

The international regulatory bodies from various regions have been emphasized the determination of impurities in the drug substances and drug products because of their toxicological concern [6, 7]. Genotoxic impurities are those that have the potential to cause cancer. These impurities (GTIs) carry to a drug substance in the manufacturing process as starting materials, reagents, intermediates, by-products, degradants, etc. If an impurity contains a structural alert for mutagenicity, it can be considered as a genotoxic impurity $[8,9]$. The European Medicines Agency released guidelines on the control of GTI and ICH also released guidelines on Genotoxic impurities [ICH M7] [10,11]. These guidelines proposed a threshold of toxicological concern value $(1.5 \mu \mathrm{g} / \mathrm{d})$.

According to the guidelines of regulatory agencies, the amount of these four genotoxic impurities in the Atazanavir sulfate should be limited to $3.75 \mathrm{ppm}$ by assuming of maximum daily dosage of Atazanavir sulfate as $400 \mathrm{mg} /$ day dose [12-14]. Accurate determination of very low level i.e., ppm levels, the hyphenated techniques are very inadequate, and consequently, there is a great need to develop a sensitive analytical method for the analysis of such genotoxic impurities in pharmaceutical industries. Thus, various kinds of separation techniques, methodologies have been explored as useful approaches out of Hsieh and Korfmacher [15], and Lee and Kerns [16] had discussed LC-MS/MS technique and application.

Several research papers have been reported in the literature for the determination of Atazanavir sulfate stability indicative methods by HPLC [17-23]. No methodology was available for Acid impurity and Keto impurity at individuals and also for the combination of four genotoxic impurities as well. The structures of Atazanavir sulphate and four genotoxic impurities are presented in fig. 1.

\section{MATERIALS AND METHODS}

Chemicals

Acetonitrile and methanol with HPLC grade were obtained from Merck (Mumbai, India). Ammonium acetate of analytical grade was supplied by Sigma Aldrich Limited (Mumbai, India). Atazanavir Sulfate API and reference substances of genotoxic impurities were obtained from HTS Biopharma, Hyderabad. 


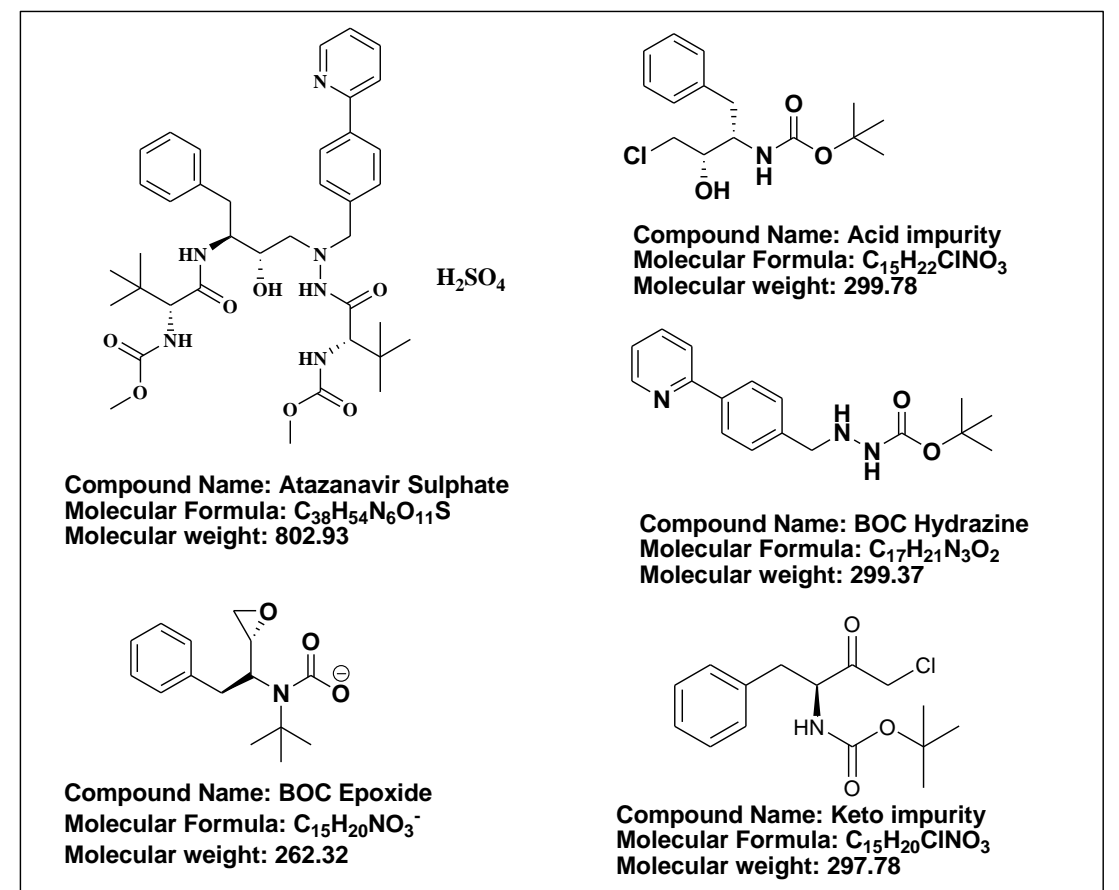

Fig. 1: Chemical structures of atazanavir sulfate and its genotoxic impurities

\section{Instrumentation}

The MS of LC-MS/MS system used was an Mass Quattro micro API model (Waters). The ultra-performance liquid chromatography (UPLC) with photodiode array detector (Waters, Milford, US). As part of experimentation, additional equipment such as sonicator (22L500/CC/DTX) and Semi microbalance (MX3, Mettler Toledo, Switzerland) was also used for method development and validation. Data acquisition and processing were conducted using the Masslynx 4.1 software on a Dell computer.

\section{Chromatographic and mass conditions}

Results were obtained in gradient mode using a mobile phase consisting of a degassed mixture of $10 \mathrm{mM}$ Ammonium acetate in water as mobile phase A, Methanol, and acetonitrile in the ratio of 90:10. Other conditions include column: Acquity UPLC CSH $\mathrm{C}_{18}(100$ $\mathrm{mm} \times 2.1 \mathrm{~mm}, 1.7 \mu \mathrm{m}$ ) (make: waters), Column temperature: $45^{\circ} \mathrm{C}$, flow rate: $0.2 \mathrm{ml} / \mathrm{min}$, injection volume: $7.0 \mu \mathrm{l}$.

The all four impurities ionization in a positive mode in the presence of electrospray ionization with the scan range of 50 to $1000 \mathrm{~m} / \mathrm{z}$. Remaining parameters Include Capillary voltage $(\mathrm{kV}): 2.0$, Cone voltage (V): 30 , Source temperature: $120{ }^{\circ} \mathrm{C}$, Desolvation temperature: $500{ }^{\circ} \mathrm{C}$, Desolvation gas $(\mathrm{L} / \mathrm{h}): 1000$ and scan type: Multiple reaction monitoring (MRM)

\section{Method development and optimization}

The present liquid chromatography-tandem mass spectrometry method was initiated by testing different stationary phases to achieve good separation of the four genotoxic impurities with the Atazanavir drug substance [29]. It is important to achieve proper separation among the four potential genotoxic impurities (PGI's) and Atazanavir sulfate because of the analogous chemical structure of four genotoxic impurities with Atazanavir sulfate [30, 31]. Initially, the method started with a mobile phase consisting of mobile phase $A$ and mobile phase $B$ in equal proportions in isocratic mode by using C18column, but keto impurity was not eluted till 15 min. In order to obtain well separation within a short analysis time, various analytical columns like Kinetex C18 $(150 \mathrm{~mm} \times 2.1 \mathrm{~mm}, 1.7$ $\mu \mathrm{m})$, Hypersil gold (100 mm $\times 2.5 \mathrm{~mm}, 1.9 \mu \mathrm{m})$, Acquity UPLC CSH C18 $(100 \mathrm{~mm} \times 2.1 \mathrm{~mm}, 1.7 \mu \mathrm{m})$ with gradient programme were evaluated under the similar conditions. When the Kinetex C18 column was used, the Keto impurity peak overlapped with
Atazanavir peak. The resolution between Atazanavir and impurities was poor when the Hypersil gold column was used. An Acquity UPLC CSH C18 $(100 \mathrm{~mm} \times 2.1 \mathrm{~mm}, 1.7 \mu \mathrm{m})$, the resolution of four genotoxic impurities, and Atazanavir were found good along with good mass sensitivity. Finally, the analysis was carried out on Acquity UPLC CSH C18 as retention and separation of four genotoxic impurities from Atazanavir drug substance were good. Different compositions of mobile phases using $0.1 \%$ formic acid and $10 \mathrm{mM}$ ammonium acetate with acetonitrile were tested. Finally, good separation and response were observed when mobile phase consisting of mobile phase A (10 $\mathrm{mM}$ ammonium acetate) mobile phase B (methanol: acetonitrile $(90: 10, \mathrm{v} / \mathrm{v}))$ with gradient run. The column was thermostated at $45{ }^{\circ} \mathrm{C}$ to avoid any shift in retention time and better peak shape.

\section{Optimization of MS/MS conditions}

Here LC/MS/MS analysis started with electrospray ionization (ESI) source in positive mode with multiple reaction monitoring (MRM). Generally, MRM mode shows high sensitivity than single ion monitoring (SIM). Multiple reaction monitoring has one more advantage than SIM mode that both parent ion and fragment ion monitored in a single analysis, but in the case of SIM mode, only a single ion i.e., either parent or daughter ion only, can monitor.

BOC Hydrazine was injected and found its $\mathrm{m} / \mathrm{z}$ as 300 (protonated) then it is fragmented with 30 volts of collision energy found more predominant stable fragment ion with its $\mathrm{m} / \mathrm{z}$ of 168.1 (daughter ion). Finally, BOC hydrazine was monitored with its mass transition between $\mathrm{m} / \mathrm{z}$ of 300 to 168.1. BOC Epoxide was injected and found its protonated ion with sodium adduct $(\mathrm{m} / \mathrm{z}$ as 286.2$)$ with lower sensitivity and fragmented ion of $\mathrm{m} / \mathrm{z} 164.1$ with high sensitivity. So fragmented ion of $\mathrm{m} / \mathrm{z}$ of 164.1 further fragmented with 30 volts of collision energy to get predominant stable fragment ion $\mathrm{m} / \mathrm{z}$ of 129.1 (daughter ion), so BOC Epoxide was monitored with its mass transition from $\mathrm{m} / \mathrm{z}$ of 164.1 to 129.1 . Acid impurity was injected and found its $\mathrm{m} / \mathrm{z}$ as 322 for a protonated ion with sodium adduct, further it is fragmented with 30 volts of collision energy and found more predominant stable fragment ion with $\mathrm{m} / \mathrm{z}$ of 200.16 as a daughter ion, so Acid impurity was monitored with its mass transition from 322 to 200.2 . Keto impurity was injected and found its $\mathrm{m} / \mathrm{z}$ as 320 for a protonated ion with sodium adduct, further it is fragmented with 30 volts of collision energy and found more predominant stable energy and found more predominant stable 
fragment ion with $\mathrm{m} / \mathrm{z}$ of 198.2 as a daughter ion, so Keto impurity was monitored with its mass transition from 322 to 200.2 .

\section{Preparation of solutions}

Diluent: Used a degassed mixture of methanol and water in the ratio of $85: 15 \mathrm{v} / \mathrm{v}$.

\section{Preparation of standard stock solution}

Accurately weighed and transferred $25 \mathrm{mg}$ of each genotoxic reference standard taken separately into four different individual $100 \mathrm{ml}$ volumetric flasks and diluted up to the mark to get 0.25 $\mathrm{mg} / \mathrm{ml}$ of stock solution. Further, each $0.5 \mathrm{ml}$ of the above solutions taken into a $100 \mathrm{ml}$ volumetric flask and diluted with diluent Further diluted $5 \mathrm{ml}$ above solution into a $50 \mathrm{ml}$ volumetric flask and diluted with diluent.

\section{Preparation of standard solution}

$1.5 \mathrm{ml}$ of the above standard stock solution is taken into $50 \mathrm{ml}$ volumetric flask and diluted up to the mark with diluent to get the standard solution of $0.00000375 \mathrm{mg} / \mathrm{ml}$, which is equivalent to 3.75 ppm with respect to sample concentration of $1 \mathrm{mg} / \mathrm{ml}$.

\section{Spiked (specification level) sample preparation}

Accurately weighed and transferred $50 \mathrm{mg}$ of Atazanavir sulfate into a $50 \mathrm{ml}$ volumetric flask to get the sample concentration of $1 \mathrm{mg} / \mathrm{ml}$, to this $1.5 \mathrm{ml}$ standard stock solution was added and diluted to volume with diluent.

\section{Sample preparation}

Weighed about $50 \mathrm{mg}$ of Atazanavir sulfate into $50 \mathrm{ml}$ volumetric flask dissolved and diluted to volume with diluent.

\section{RESULTS AND DISCUSSION}

Research papers available for individual genotoxic impurities of BOC Hydrazine [24]. The reported method containing isocratic elution and used the single ion monitoring (SIM) method by HPLC-MS. For this method, the quantification limit is $1.1 \mathrm{ppm}$ and run time $15 \mathrm{~min}$.

According to literature [25], the authors reported that, the BOC epoxide impurity was found quantification limit was $0.5 \mathrm{ppm}$ by isocratic mode and run time was 15 min through HPLC. In this published paper, the authors are not used the multiple reaction monitoring (MRM) technique for the detection of stable fragments.

In the present study, we developed a simple LC-MS/MS method that can quantify (below $0.3 \mathrm{ppm}$ ) the BOC Hydrazine, BOC Epoxide, Acid impurity, and Keto impurity at a lower level in Atazanavir sulphate. Analysis was carried out with gradient mode and multiple reaction monitoring (MRM) method for the detection of stable fragments to improve the sensitivity. The MRM fragmentation shown in below mention below.<smiles>CC(C)(C)N(C(=O)[O-])C(Cc1ccccc1)C1CO1</smiles><smiles>CC(C)(C)OC(=O)NNCc1ccc(-c2ccccn2)cc1</smiles><smiles>CCNC(=O)OC(C)(C)C</smiles><smiles>CCC(=O)C(N)Cc1ccc(C(C)(C)C)cc1</smiles>

Fig. 2: Fragmentation of genotoxic impurities

As per the literature review, this is the first LC-MS/MS method developed for the determination for the detection and quantification of BOC Hydrazine, BOC Epoxide, Acid impurity, and Keto impurity simultaneously. The method is validated as per ICH guidelines in terms of limit of detection (LOD), the limit of quantification (LOQ), linearity, precision, accuracy, specificity, and robustness [26-28].

\section{Method validation}

Validation provides assurance about the method or process regarding the quality standard of the analytical method is assured by performing the validation of the developed method withQ2 specifications of ICH guidelines.

\section{System suitability}

The system suitability test was performed before each run to assure that the developed LC-MS/MS method exhibits satisfactory performance. It is evaluated by injecting the six injections of standard solution and calculating the \% RSD of areas of all impurities. The data generated in this test is presented in table 1.

Table 1: System suitability results of four genotoxic impurities

\begin{tabular}{|c|c|c|c|c|}
\hline S. No. & Components & Average area $(\mathrm{n}=6)^{*}$ & SD & $\%$ RSD \\
\hline 1 & BOC Hydrazine & 306484 & 4866.2 & 1.59 \\
\hline 2 & BOC Epoxide & 114023 & 1678.8 & 1.47 \\
\hline 3 & Acid impurity & 120626 & 1197.3 & 0.99 \\
\hline 4 & Keto impurity & 99387 & 1878.7 & 1.89 \\
\hline
\end{tabular}

*Number of injections done (n):6.

\section{Specificity}

Specificity of the present LC-MS/MS method was checked by injecting the blank, four individual genotoxic impurities and Atazanavir sulfate sample and sample spiked with four genotoxic impurities. There was no interference of the main drug with impurities and the developed method was adequately resolved four genotoxic impurities with each other and with the main drug. Results presented in table 2 and representative spectra presented in fig. 3. 
Table 2: Summary of specificity

\begin{tabular}{llll}
\hline Name of the component & RT (min) $^{*}$ & m/z molecular ion (Protonated) & m/z fragment ion (Protonated) \\
\hline BOC Hydrazine & 4.5 & 300.1 & 168.1 \\
Acid impurity & 6.2 & $322[\mathrm{M}+\mathrm{Na}]$ & 200.1 \\
BOC Epoxide & 6.9 & $286[\mathrm{M}+\mathrm{Na}]$ & 164.1 \\
Keto impurity & 8.6 & $320[\mathrm{M}+\mathrm{Na}]$ & 198.1 \\
Atazanavir & 10.0 & 705.3 & -- \\
\hline
\end{tabular}

*RT-Retention time

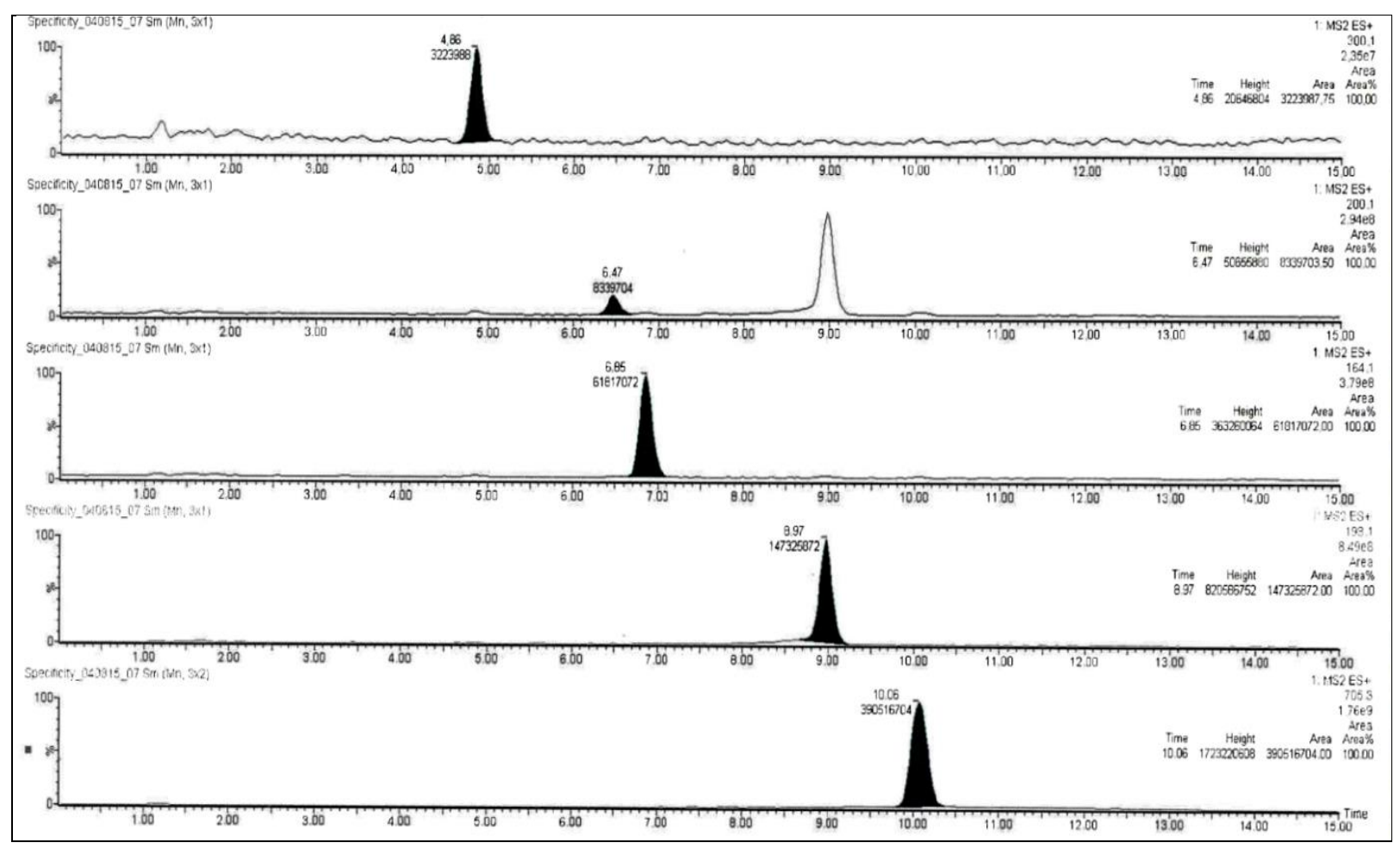

Fig. 3: Chromatograms of the specificity of the impurities with atazanavir

\section{Linearity and sensitivity}

The linearity of the method in multiple reaction monitoring mode was satisfactorily demonstrated by injecting the four genotoxic impurities individually at different levels of concentrations ranges from LOQ (0.3 ppm) and $120 \%(4.5 \mathrm{ppm})$ of the specification concentration ( $3 \mathrm{ppm})$. The calibration curves were plotted between the peak areas and concentration of four genotoxic impurities at include $0.3,1.5,2.25,3$, and 4.5 ppm for LOQ, 40, 60, 80, 100, $120 \%$ specification levels, respectively.

The limit of detection (LOD) and limit of quantification (LOQ) were calculated from $\mathrm{S} / \mathrm{N}$ (signal to noise) ratios. In this process, the concentrations were reduced sequentially in such a way to yield an $\mathrm{S} / \mathrm{N}$ ratio. Results are represented in table 3 and linearity curves in fig. 4.

Table 3: Linearity and sensitivity results of four genotoxic impurities

\begin{tabular}{|c|c|c|c|c|}
\hline Parameter & BOC hydrazine & Acid impurity & BOC epoxide & Keto impurity \\
\hline Range (ppm) & $0.298-4.459$ & $0.299-4.468$ & $0.298-4.458$ & $0.288-4.475$ \\
\hline Correlation* & 0.9998 & 0.9995 & 0.9995 & 0.9996 \\
\hline Slope $e^{* *}$ & 97662.466 & 35021.962 & 31352.230 & 30996.371 \\
\hline Intercept & -5486.091 & -1861.835 & 891.973 & 1556.560 \\
\hline LOD (ppm) & 0.10 & 0.10 & 0.11 & 0.10 \\
\hline $\mathrm{S} / \mathrm{N}$ & 3.4 & 2.5 & 2.8 & 3.3 \\
\hline LOQ (ppm) & 0.298 & 0.299 & 0.298 & 0.288 \\
\hline $\mathrm{S} / \mathrm{N}$ & 10.4 & 9.9 & 9.8 & 10.5 \\
\hline \multicolumn{5}{|c|}{ LOQ Precision $(n=6)^{\#}$} \\
\hline Mean area & 27120 & 11073 & 12141 & 10227 \\
\hline SD & 656.6193 & 410.5604 & 244.8031 & 338.7034 \\
\hline$\%$ RSD & 2.42 & 3.71 & 2.02 & 3.31 \\
\hline
\end{tabular}

${ }^{*}$ Correlation coefficient, ${ }^{* *} \mathrm{Y}$ is the peak area, and $\mathrm{X}$ is the concentration has taken, ${ }^{*}$ Number of experiments done (n):6 


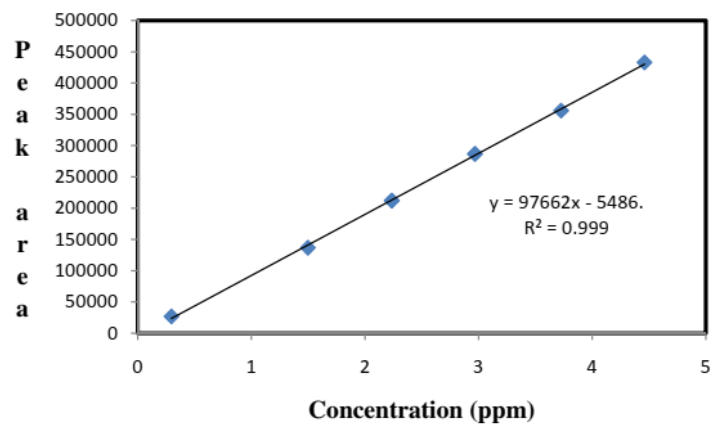

BOC hydrazine

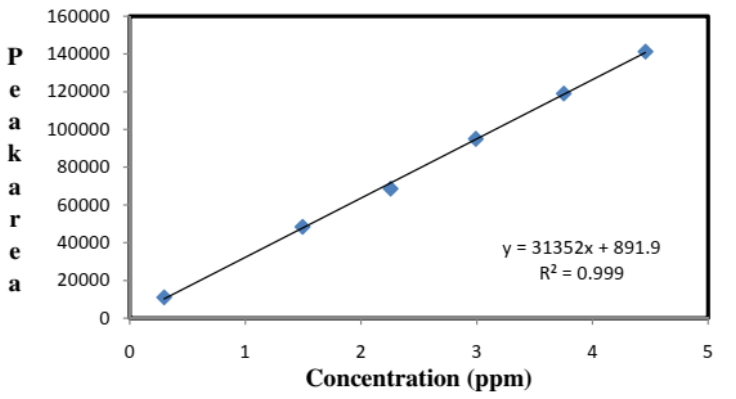

BOC epoxide

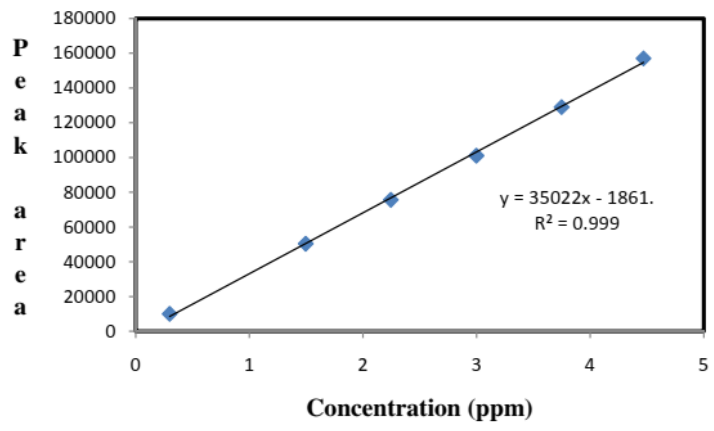

Acid impurity

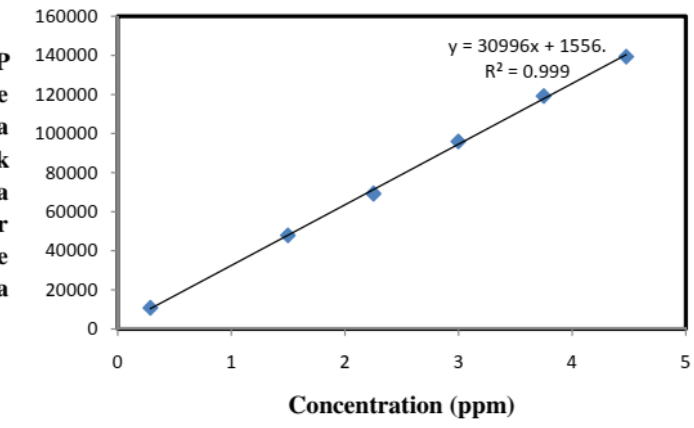

Keto impurity

Fig. 4: Linearity curves of genotoxic impurities

\section{Precision}

The precision of the method was determined by analyzing six individual samples of Atazanavir spiked with each impurity at $100 \%$ of the specification limit on the same day, and Intermediate precision was evaluated by analyzing six individual samples of Atazanavir spiked with each impurity at $100 \%$ of the specification limit on the other day. The obtained results were given in table 4 and the representative chromatogram in fig. 5.

\section{Accuracy}

To ensure the accuracy of the method, a Percentage recovery technique was adopted where spiking the four genotoxic impurities at LOQ level, $50 \%, 100 \%$, and $120 \%$ of the specification concentrations i.e., $0.3,1.875,3.75$, and $4.5 \mathrm{ppm}$ with respect to the sample concentration of $1 \mathrm{mg} / \mathrm{ml}$ of Atazanavir. Each determination was carried out in triplicate. The percentage recovery values obtained at LOQ to $120 \%$ levels were in the range of $99.3-105.7$ (table 5,6 ), which significantly gives out the accuracy of the concerned method as of ICH limits.

\section{Robustness}

The robustness of the present LC-MS/MS method was checked by deliberate changes in flow rate and column temperature in liquid chromatography and source temperature in the mass source. The effect of the flow rate of the mobile phase on the separation of three genotoxic impurities was studied by changing the actual flow $(0.2$ $\mathrm{ml} / \mathrm{min}$ ) rate by $10 \%$, i.e., at 0.18 and $0.22 \mathrm{ml} / \mathrm{min}$. The effect of column temperature on the analysis was studied by changing the temperature by two units, i.e., at $42{ }^{\circ} \mathrm{C}$ and $47^{\circ} \mathrm{C}$ (temperature altered by two units). The robustness of the proposed method was also evaluated by changing the temperature in the mass source with $\pm 20{ }^{\circ} \mathrm{C}$. Results obtained from robustness were mention in tables 7 to 10 .

Table 4: Method precision and intermediate precision results of four impurities

\begin{tabular}{|c|c|c|c|c|}
\hline Parameter & BOC hydrazine & Acid impurity & BOC epoxide & Keto impurity \\
\hline \multicolumn{5}{|c|}{ Method precision $(n=6)^{*}$} \\
\hline Mean (ppm) & 3.84 & 3.58 & 3.32 & 3.59 \\
\hline SD & 0.0350 & 0.0426 & 0.0308 & 0.0383 \\
\hline$\%$ RSD & 0.9 & 1.2 & 0.9 & 1.1 \\
\hline \multicolumn{5}{|c|}{ Intermediate precision $(n=6)^{*}$} \\
\hline Mean (ppm) & 3.62 & 3.71 & 3.44 & 3.72 \\
\hline SD & 0.0647 & 0.0539 & 0.0605 & 0.0736 \\
\hline$\%$ RSD & 1.8 & 1.5 & 1.8 & 2.0 \\
\hline \multicolumn{5}{|c|}{ Cumulativeprecision $(n=12)^{\#}$} \\
\hline Mean (ppm) & 3.73 & 3.65 & 3.38 & 3.65 \\
\hline SD & 0.1251 & 0.0829 & 0.0755 & 0.0893 \\
\hline \%OverallRSD & 3.4 & 2.3 & 2.2 & 2.4 \\
\hline
\end{tabular}

*Number of experiments done (n):6, \#Number of experiments done (n):12 (cumulative results of both method precision and intermediate precision. 


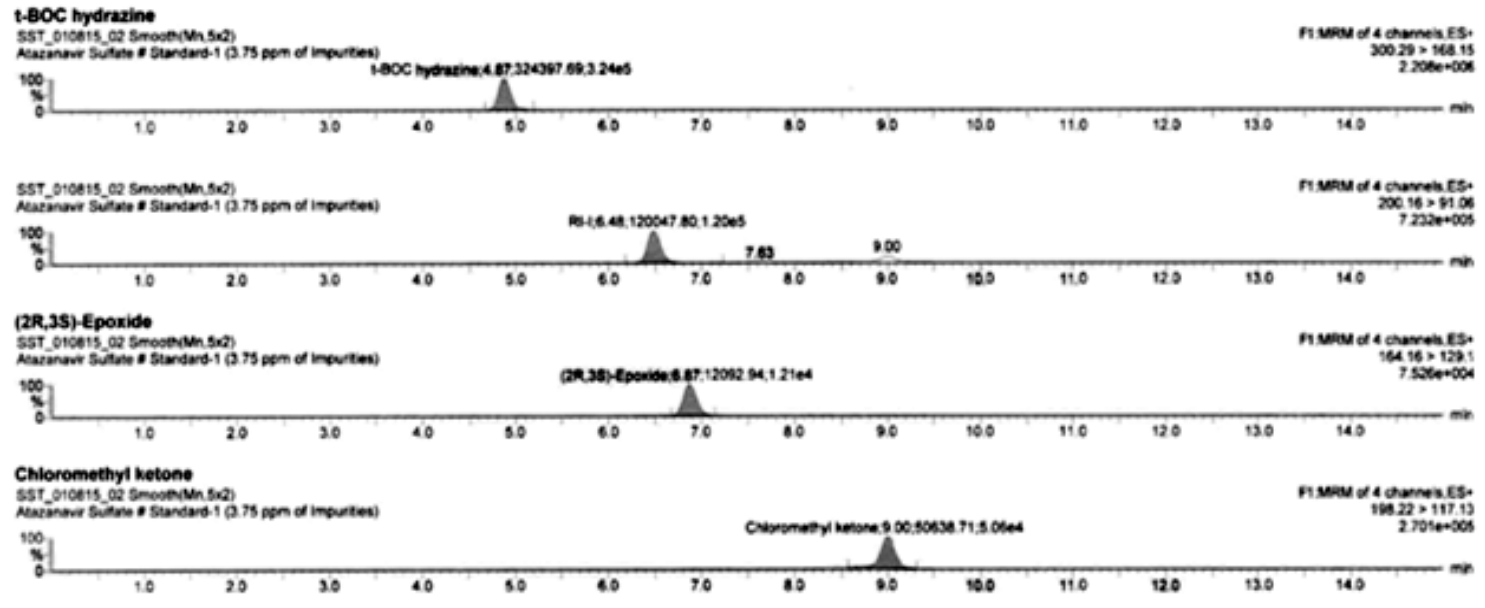

Fig. 5: Representative chromatograms of the precision

Table 5: Accuracy results of four impurities at LOQ level

\begin{tabular}{|c|c|c|c|c|c|c|}
\hline Component & Amount added (ppm) & Amount found (ppm) & \% Recovery & Mean recovery & SD $^{*}$ & \%RSD \\
\hline \multicolumn{7}{|l|}{$\mathbf{n}=3^{\#}$} \\
\hline \multirow[t]{3}{*}{ BOC Hydrazine } & 0.2963 & 0.3016 & 101.79 & 101.0 & 0.674 & 0.7 \\
\hline & 0.2986 & 0.3004 & 100.60 & & & \\
\hline & 0.2956 & 0.2975 & 100.64 & & & \\
\hline \multirow[t]{3}{*}{ Acid impurity } & 0.2971 & 0.3010 & 101.31 & 101.5 & 0.445 & 0.4 \\
\hline & 0.2946 & 0.3008 & 102.10 & & & \\
\hline & 0.2956 & 0.3092 & 104.60 & & & \\
\hline \multirow[t]{3}{*}{ BOC Epoxide } & 0.2897 & 0.2956 & 102.04 & 102.8 & 1.115 & 1.1 \\
\hline & 0.2946 & 0.3012 & 102.24 & & & \\
\hline & 0.2856 & 0.2972 & 104.06 & & & \\
\hline \multirow[t]{3}{*}{ Keto impurity } & 0.2997 & 0.3010 & 100.43 & 100.8 & 0.329 & 0.3 \\
\hline & 0.2986 & 0.3012 & 100.87 & & & \\
\hline & 0.2965 & 0.2997 & 101.08 & & & \\
\hline
\end{tabular}

*Standard deviation, "Number of experiments done (n):3

Table 6: Accuracy results of four genotoxic impurities

\begin{tabular}{|c|c|c|c|c|c|c|}
\hline \multirow{2}{*}{\multicolumn{7}{|c|}{$\begin{array}{l}\% \text { of spec } \\
n=3^{*} n=9^{*}\end{array}$}} \\
\hline & & & & & & \\
\hline BOC Hydrazine & & & & 103.4 & 1.108 & 1.1 \\
\hline $50 \%$ & 1.8491 & 1.8803 & 101.7 & & & \\
\hline $100 \%$ & 3.6376 & 3.7672 & 103.6 & & & \\
\hline $120 \%$ & 4.3533 & 4.5612 & 104.8 & & & \\
\hline Acid impurity & & & & 101.8 & 0.680 & 0.7 \\
\hline $50 \%$ & 1.8599 & 1.8884 & 101.5 & & & \\
\hline $100 \%$ & 3.6603 & 3.7562 & 102.6 & & & \\
\hline $120 \%$ & 4.3822 & 4.4379 & 101.3 & & & \\
\hline BOC Epoxide & & & & 101.0 & 0.909 & 0.9 \\
\hline $50 \%$ & 1.7774 & 1.7760 & 99.9 & & & \\
\hline $100 \%$ & 3.5795 & 3.6892 & 103.1 & & & \\
\hline $120 \%$ & 4.1897 & 4.1925 & 100.1 & & & \\
\hline Keto impurity & & & & 102.1 & 0.680 & 0.7 \\
\hline $50 \%$ & 1.8498 & 1.8705 & 101.1 & & & \\
\hline $100 \%$ & 3.6603 & 3.7562 & 102.6 & & & \\
\hline $120 \%$ & 4.3499 & 4.4617 & 102.6 & & & \\
\hline
\end{tabular}

${ }^{*}$ Number of experiments done at each level (n):3, cumulative recovery for all three levels (n):9

Table 7: Robustness impact on BOC hydrazine from system suitability solution

\begin{tabular}{llll}
\hline Parameter & Variation & Retention time (min) & \%RSD \\
\hline Actual & -- & 4.5 & 1.59 \\
Flow rate $( \pm 10 \%)$ & $0.18 \mathrm{ml} / \mathrm{min}$ & 4.7 & 1.03 \\
& $0.22 \mathrm{ml} / \mathrm{min}$ & 4.3 & 0.69 \\
ColumnOven temp $( \pm 2$ units) & $42^{\circ} \mathrm{C}$ & 4.6 & 1.24 \\
& $47^{\circ} \mathrm{C}$ & 4.3 & 0.97 \\
Desolvation temperature and gas & 980 & 4.5 & 1.24 \\
& 1020 & 4.5 & 1.02 \\
\hline
\end{tabular}


Table 8: Robustness impact on acid impurity from system suitability solution

\begin{tabular}{llll}
\hline Parameter & Variation & Retention time (min) & \%RSD \\
\hline Actual & -- & 6.2 & 0.99 \\
Flow rate $( \pm 10 \%)$ & $0.18 \mathrm{ml} / \mathrm{min}$ & 6.8 & 1.47 \\
& $0.22 \mathrm{ml} / \mathrm{min}$ & 6.0 & 2.68 \\
ColumnOven temp $( \pm 2$ units) & $42^{\circ} \mathrm{C}$ & 6.7 & 1.14 \\
& $47^{\circ} \mathrm{C}$ & 6.0 & 0.89 \\
Desolvation temperature and gas & 980 & 6.2 & 3.41 \\
& 1020 & 6.2 & 1.15 \\
\hline
\end{tabular}

Table 9: Robustness impact on BOC epoxide from system suitability solution

\begin{tabular}{llll}
\hline Parameter & Variation & Retention time (min) & \%RSD \\
\hline Actual & -- & 6.9 & 1.47 \\
Flow rate $( \pm 10 \%)$ & $0.18 \mathrm{ml} / \mathrm{min}$ & 7.1 & 1.81 \\
& $0.22 \mathrm{ml} / \mathrm{min}$ & 6.7 & 0.60 \\
ColumnOven temp $( \pm 2$ units) & $42{ }^{\circ} \mathrm{C}$ & 6.6 & 0.92 \\
& $47^{\circ} \mathrm{C}$ & 6.9 & 1.49 \\
Desolvation temperature and gas & 980 & 6.9 & 1.15 \\
& 1020 & 6.9 & 1.24 \\
\hline
\end{tabular}

Table 10: Robustness impact on Keto impurity from system suitability solution

\begin{tabular}{llll}
\hline Parameter & Variation & Retention time (min) & \%RSD \\
\hline Actual & -- & 8.7 & 1.89 \\
Flow rate $( \pm 10 \%)$ & $0.18 \mathrm{ml} / \mathrm{min}$ & 8.9 & 3.58 \\
& $0.22 \mathrm{ml} / \mathrm{min}$ & 8.5 & 1.43 \\
ColumnOven temp $( \pm 2$ units) & $42^{\circ} \mathrm{C}$ & 8.9 & 1.20 \\
& $47^{\circ} \mathrm{C}$ & 8.6 & 1.48 \\
Desolvation temperature and gas & 980 & 8.7 & 0.94 \\
& 1020 & 8.7 & 1.54 \\
\hline
\end{tabular}

\section{Solution stability}

To prove the stability of these four impurities, standard solution and the spiked solution were kept at refrigerator $\left(2-8^{\circ} \mathrm{C}\right)$ conditions and room temperature $\left(25^{\circ} \mathrm{C}\right)$ for $24 \mathrm{~h}$. It was found that the amount recovered from both fresh and stored solutions was highly similar.

\section{CONCLUSION}

In the earlier period, a number of RP-HPLC were developed for estimation of Atazanavir sulfate and its impurities in pure and dosage form. Only two LC-MS/MS methods were reported for the determination of GTI's such as BOC Hydrazine and epoxide. But single LC-MS/MS method for estimation of all the four GTI's was not yet established. The present LC-MS/MS method has the ability to separate and quantify all the four GTI's at trace level. The RT gained for all the four GTI's was less with the simple solvent system in gradient mode. Therefore the method has good adaptability in the pharmaceutical industry for analysis of Atazanavir sulfate.

\section{ACKNOWLEDGEMENT}

We sincerely thank the department of chemistry, GITAM School of Science, GITAM (Deemed to be University), Hyderabad, for providing $\mathrm{Ph}$. D. registration and facilities.

\section{FUNDING}

Nil

\section{AUTHORS CONTRIBUTIONS}

Ms. Siva Jyothi. N has generated the research activity and prepared the manuscript. Dr. Venkatnarayana. $\mathrm{M}$ has given guidance and supervision to carry out this research work.

\section{CONFLICT OF INTERESTS}

None exists in the current study.

\section{REFERENCES}

1. Drug bank online. Atazanavir drug substance. Available from: https://www.drugbank.ca/drugs/DB01072. [Last accessed on 15 Dec 2020].
2. Atazanavir drug information available in NCI Thesaurus (NCIt), with drug code Atazanavir (Code C66872); 2021.

3. Anti-HIV drugs information, PubMed and National Center for Biotechnology Information (NCBI); Atazanavir. Available from: https://www.ncbi.nlm.nih.gov/mesh/2009983. [Last accessed on 15 Dec 2020]

4. Atazanavir sulfate with the brand name; Uses dosage, side effects. Available from: https://www.rxlist.com/reyatazdrug.htm [Last accessed on 15 Dec 2020]

5. Deductive Estimation of Risk from Existing Knowledge (DEREK) nexus, marketed by LHASA Ltd, Leeds, Yorkshire UK, DEREK Version Derek: 3.0.1; Nexus; 2019.

6. FDA, Draft Guidance for Industry: Genotoxic and Carcinogenic Impurities in Drug Substances and Products: Recommended Approaches, CDER, Silver Spring, MD, USA; 2008.

7. International Conference on Harmonization Q3A-Q3D: Impurities-International Council for Harmonization guidelines; 2006. p. 1-11.

8. Vijaya Bhaskar Reddy A, Jaafar J, Umar K, Abdul Majid Z, Azmi Bin A, Talib J, et al. Identification, control strategies, and analytical approaches for the determination of potential genotoxic impurities in pharmaceuticals: a comprehensive review. J Sep Sci 2015;38:764-79.

9. Lee H. Pharmaceutical industry practices on genotoxic impurities, CRC Press: Boca Raton, FL USA; 2014.

10. European Directorate for the Quality of Medicines and HealthCare (EDQM), the European Pharmacopeia, EDQM, Strasbourg, France. $9^{\text {th }}$ edition; 2017.

11. ICH, "M7 (R1): assessment and control of DNA reactive (mutagenic) impurities in pharmaceuticals to limit potential carcinogenic risk," In Proceedings of the International Conference on Harmonisation (ICH), Geneva, Switzerland; 2017.

12. McGovern T, Jacobson Kram D. Regulation of genotoxic and carcinogenic impurities in drug substances and products. Trends Anal Chem 2006;25:790-5.

13. Muller L, Mauthe RJ, Riley CM, Andino MM, Antonis DD, Beels. Nationale for determining, testing, and controlling specific impurities in pharmaceuticals that posses potential for genotoxicity, reg. Toxicol Pharmacol 2006;44:198-11. 
14. Raman NVVSS, Prasad AVVS, Reddy KV. Strategies for the identification, control, and determination of genotoxic impurities in drug substances: a pharmaceutical industry perspective. J Pharm Biomed 2011;55:662-7.

15. Hsieh Y, A Korfmacher W. Increasing speed and throughput when using HPLC-MS/MS systems for drug metabolism and pharmacokinetic screening. Curr Drug Metab 2006;7:479-80.

16. Lee MS, Kerns EH. LC/MS applications in drug development Mass Spectrom Rev 1999;18:187-9.

17. Chitttturi SR, Somannavar YS, Peruri BG, Nallapati S, Sharma HK, Budider SR, et al. Gradient RP-HPLC method for the determination of potential impurities in atazanavir sulphate. ] Pharm Biomed Anal 2011;55:31-7.

18. Bhirud CH, Hiremath SN. Stability indicating RP-HPLC method for the determination of atazanavir sulphate in bulk and dosage form. Drug Invent Today 2013;5:81-6.

19. Dey S, Subhasis Patro S, Suresh Babu N, Murthy PN. Development and validation of a stability-indicating RP-HPLC method for estimation of Atazanavir sulfate in bulk. J Pharm Anal 2013;12:1-2.

20. Devi PR, Mukkanti K, Srinivasarao K. Simultaneous estimation of atazanavir sulfate and ritonavir by RP-HPLC method in combined tablet dosage forms and it's in vitro dissolution assessment Novus. Int J Anal 2012;1:5-14.

21. Srinivasu K, Rao JV, Raju NA. A validated RP-HPLC method for the determination of atazanavir in pharmaceutical dosage form. E J Chem 2011;8:453-6.

22. Dey S, Reddy YV, Reddy T. Method development and validation for the estimation of atazanavir in bulk and pharmaceutical dosage forms and its stress degradation studies using UV-VIS spectrophotometric method. Int J Pharm Bio Sci 2010;1:1-12.
23. Mastanamma SK, Kumar A, Srivani G, Sridhar T, Sankar Naik B, Kumar V. Stability indicating validated reverse phase-high performance liquid chromatography method for simultaneous determination of Cobicistat and Atazanavir sulfate in bulk and pharmaceutical dosage form. Asian I Pharm Clin Res 2016;9:62-70

24. Subbaiah N, Subba reddy GV. Method development and validation by LC-MS for trace level quantification of BOC epoxide in atazanavir sulphate. Int J Pharm Pharm Sci 2017;9:143-8.

25. Geeta Bhavani K, Srinivasu N. Determination of genotoxic impurity in atazanavir sulphate substance by LC-MS, J Pharm Biomed Anal 2017;132:156-8.

26. Guideline for Validation of Analytical Procedures, Q2(R1), ICH; 2003.

27. The International Conference on Harmonization, Q1 (A) R2, Stability testing of new drug substances, Current step 4 versions; 2003.

28. United States Pharmacopeia 28-NF 23. The United States Pharmacopoeial Convention Inc. Rockville, MD; 2005. p. 748.

29. Narasimha Rao L, Devanna N, Suresh Reddy KVN. Method development and validation study for the quantitative determination of genotoxic impurity and its precursor in fluconazole sample by liquid chromatography-tandem mass spectroscopy. Int J Pharm Pharm Sci 2016;8:84-9.

30. Mohammad A, Al-Sayah. Analytical strategies for genotoxic impurities in the pharmaceutical industry. In American Pharmaceutical Review; 2014.

31. Derek I Robinson. Control of genotoxic impurities in active pharmaceutical ingredients: a review and perspective. Org Process Res Dev 2010;14:946-59. 